OPEN ACCESS

Edited by:

Kequan $\mathrm{Yu}$,

Tongji University, China

Reviewed by:

Shuai Fang,

South China University of Technology,

China

Jie Xiao,

Guangdong University of Technology,

China

${ }^{*}$ Correspondence:

Hongguo Ren

renhongguo771126@163.com

Specialty section:

This article was submitted to

Structural Materials,

a section of the journal

Frontiers in Materials

Received: 28 February 2021

Accepted: 16 March 2021

Published: 08 April 2021

Citation:

Ji J, Song H, Jiang L, Ren H,

Zhang $Y$ and Liu $Y$ (2021) Tensile

Performance of High Ductility

Cementitious Composites With

Recycled Powder From C\&D Waste.

Front. Mater. 8:673752.

doi: 10.3389/fmats.2021.673752

\section{Tensile Performance of High Ductility Cementitious Composites With Recycled Powder From C\&D Waste}

\author{
Jing Ji1,2, Huayu Song ${ }^{1}$, Liangqin Jiang ${ }^{1}$, Hongguo Ren ${ }^{3 *}$, Yunfeng Zhang ${ }^{1,2}$ and \\ Yingchun Liu ${ }^{1,2}$
}

${ }^{1}$ Heilongjiang Key Laboratory of Disaster Prevention, Mitigation and Protection Engineering, Northeast Petroleum University, Daqing, China, ${ }^{2}$ Key Laboratory of Earthquake Engineering and Engineering Vibration, Institute of Engineering Mechanics, China Earthquake Administration, Harbin, China, ${ }^{3}$ Handan Key Laboratory of Building Physical Environment and Regional Building Protection Technology, School of Architecture and Art, Hebei University of Engineering, Handan, China

The effects of recycled powder (RP) on hydration, micro-structures, compressive strength and tensile properties of high-ductility cementitious composites (HDCC) were studied. Three mass ratios of RP ranging from 10, 30 to $60 \%$ were employed to partially replace the cement. The hydration kinetics of RP-amended matrix was measured to investigate the influence of RP on the cementitious hydration process and the phase development was quantified by the thermal gravimetric analysis. Mechanical properties, including the compressive and tensile properties of HDCCs were obtained at 28 days. The morphology of reinforced polyethylene fiber at the fracture surface was obtained by the environmental scanning electron microscope (SEM) analysis.

Keywords: high-ductility cementitious composites, micro-structures, mechanical properties, tensile performance, recycled powder

\section{INTRODUCTION}

Recycled powder (RP) with the particle size smaller than $150 \mu \mathrm{m}$ is a byproduct during the concrete (clay brick) crushing process. It is estimated that RP accounts for roughly $20 \%$ of the entire concrete and clay brick waste (Sun et al., 2017). These tiny grains should be properly utilized to avoid the potential pollution to the air and underground water (Xiao et al., 2016).

Over the past decades, quite a few researches have been conducted to investigate the effects of alternative cementitious materials to the mechanical properties of concrete (Li et al., 2007, 2009; Yang et al., 2007; Zhang and Zhang, 2018; Wang et al., 2019). In recent years, RP was utilized to substitute a fraction of cement in the mixture as a supplementary cementitious material like fly ash and metakaolin. It was revealed that the RP would speed up hydration at the early age while reducing total hydration heat release (Liu et al., 2014). On the basis of the micro-mechanics designing theory, the coarse aggregate in the high-ductility cementitious composites (HDCC) mixture should be removed and the sand/binder ratio was largely diminished in HDCC to ensure good fiber dispersion and thus a satisfactory strain capacity with a strain-hardening phenomenon (Yu et al., 2017, 2018; Ding et al., 2018; Ji et al., 2019). The elimination of coarse aggregate and the reduction in the sand amount consequently raised the amount of cement in HDCC. However, it is noticed that higher cement dosage in HDCC, on one hand, increased the manufacturing cost; on the other hand, led to soaring heat of hydration and lager autogenous shrinkage of HDCC, which adversely reduced the compressive and tensile performance of HDCC. 


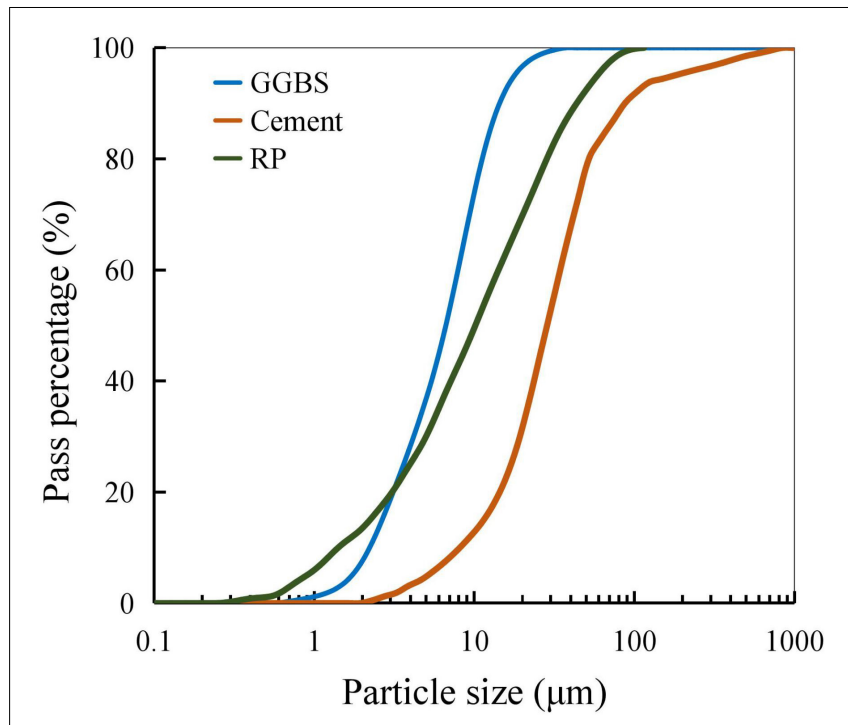

FIGURE 1 | Particle size distributions of the component.

Thus, the aim of this paper is to utilize the RP to partially replace the cement in HDCC, which could significantly reduce the amount of cement. The impact of RP particles on mechanical performance of HDCC, including the tensile and compressive performance was then discussed. The microstructures of RP-amended HDCC, including the hydration heat, thermal gravimetric analysis, and morphology of polyethylene fiber, were also investigated.

\section{TEST PREPARATION}

\section{Raw Materials and Mix Proportions}

The HDCC was consisted of three parts: cementitious binder, aggregate, and reinforced fiber. 42.5R type I Cement, ground granulated blast slag (GGBS), and RP were used as the binder constituents for HDCC. GGBS and SF particles were considered as the pozzolanic components, which would accelerate the development of hydrated calcium silicate (C-S-H). RP was utilized to partly substitute the cement owing to its potential pozzolanic function (Liu et al., 2017). The silica sand with the particle diameter of 70-120 meshes was used as the aggregate. The sand/binder ratio was controlled at a low value to ensure the fiber dispersion. The gradation curves of cementitious materials and silica sand are given in Figure 1. The diameter and length of PE fiber are $24 \mu \mathrm{m}$ and $18 \mathrm{~mm}$, respectively. The tensile strength and Young's modulus of PE fiber are 2,400 $\mathrm{MPa}$ and $100 \mathrm{GPa}$ and its elongation at breakage is $2-3 \%$. Finally, a high-range superplasticizer was effectively employed to preserve the mixture flowability at a relatively small water/cementitious binder ratio.

Tiny particles of silica fume, RP and GGBS could densify of the matrix by filling the large pores, strengthen sand-paste interface and thus enhance the matrix strength. RP particles were gathered from a recycled factory, which crushed the construction wastes including both concrete and clay bricks. $85 \% \mathrm{RP}$ particles had a

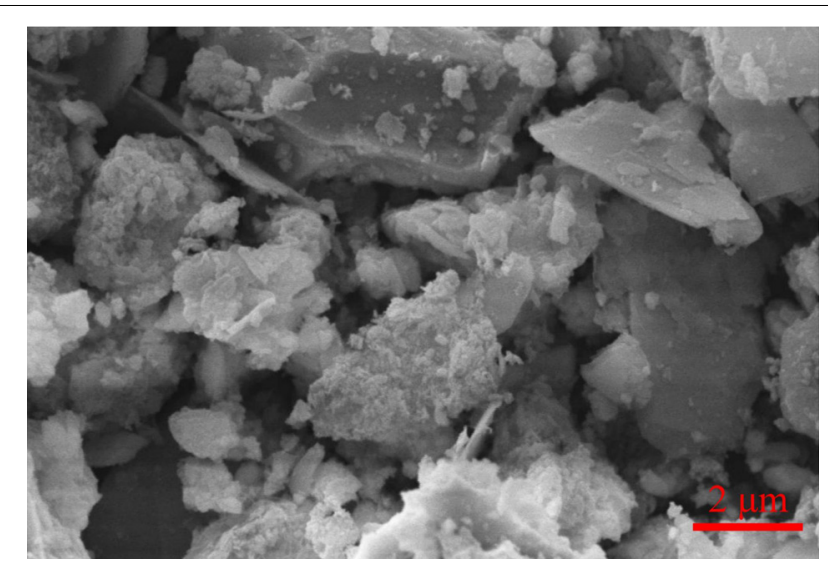

FIGURE 2 | Morphology of RP particles.

size lower than $45 \mu \mathrm{m}$, within which $42 \%$ particles were lower than $10 \mu \mathrm{m}$. The fine particles were beneficial to the strength development of matrix because of the apparent filling effect (Yu et al., 2020).

Figure 2 shows the morphology of RP particles, which has the similar irregular shapes to that of GGBS. The thermal gravimetric analysis of RP shows a trough around $680-720^{\circ} \mathrm{C}$, exhibiting a decarbonization of $\mathrm{CaCO}_{3}$ at this temperature range with the escape of $\mathrm{CO}_{2}$.

The four mixture proportions of HDCC are given in Table 1. Three replacement ratios of RP to cement dosage up to $60 \%$ by mass $(10,30$, and $60 \%)$ were employed. The water/binder ratio of all the four mixtures was fixed at 0.36 . The mixture was named as HDCC-RP-A, where A denotes as the mass ratio of RP. The fiber mass in all the mixtures was $19.4 \mathrm{~kg} / \mathrm{m}^{3}$, representing a $2 \%$ volume.

\section{Experimental Preparation}

A TAM air calorimeter was utilized to measure the hydration heat of HDCC matrix following the instruction of ASTM C170209a ASTM International (2008). A fixed volume of each matrix (around $0.1 \mathrm{~L}$ ) mixed at room temperature was rapidly put into the ampule and kept in the chamber for $72 \mathrm{~h}$. TGA/DTG analysis was conducted by Mettlery Toled TGA/SDTA 852 balance. Each dry-slice sample around $12 \mathrm{mg}$ was ground into fine powder and heated from 20 to $1,000^{\circ} \mathrm{C}$ at a fixed rate of $10^{\circ} \mathrm{C} / \mathrm{min}$.

The full-range tensile stress-strain relationship of HDCC under uniaxial tension was determined by the plain dumbbellshaped specimen (as shown in Figure 3) according to JSCE specification ${ }^{[16]}$. The dimensions of dumbbell-shaped specimen are shown in Figure 4 with a cross-section of $30 \mathrm{~mm} \times 13 \mathrm{~mm}$ and the gauge length of $80 \mathrm{~mm}$. For each case from HDCCReference to HDCC-RP-60\%, four dumbbell specimens were cast and tested to obtain their tensile properties at 28 days. The dumbbell geometry could ensure the distribution of majority cracks in the gauge length to allow a more reliable measurement of tensile strain. Cube specimens with edge length of $50 \mathrm{~mm}$ were prepared for the compression test at 28 days. The detailed 
TABLE 1 | Mix properties of HDCC.

\begin{tabular}{|c|c|c|c|c|c|c|c|c|}
\hline Mixture types $\left(\mathrm{kg} / \mathrm{m}^{3}\right)$ & $\begin{array}{l}\text { Cement } \\
\left(\mathrm{kg} / \mathrm{m}^{3}\right)\end{array}$ & $\begin{array}{c}\mathrm{RP} \\
\left(\mathrm{kg} / \mathrm{m}^{3}\right)\end{array}$ & $\begin{array}{c}\text { GGBS } \\
\left(\mathrm{kg} / \mathrm{m}^{3}\right)\end{array}$ & $\begin{array}{l}\text { Silica sand } \\
\left(\mathrm{kg} / \mathrm{m}^{3}\right)\end{array}$ & $\begin{array}{c}\text { Water } \\
\left(\mathrm{kg} / \mathrm{m}^{3}\right)\end{array}$ & $\begin{array}{l}\text { PE fiber } \\
\left(\mathbf{k g} / \mathrm{m}^{3}\right)\end{array}$ & $\begin{array}{c}\text { HRWR } \\
\left(\mathrm{kg} / \mathrm{m}^{3}\right)\end{array}$ & W/Binder \\
\hline HDCC-reference & 600 & - & 400 & 600 & 360 & 19.4 & 5 & 0.36 \\
\hline HDCC-RP-10\% & 540 & 60 & 400 & 600 & 360 & 19.4 & 5 & 0.36 \\
\hline HDCC-RP-30\% & 420 & 180 & 400 & 600 & 360 & 19.4 & 5 & 0.36 \\
\hline HDCC-RP-60\% & 240 & 360 & 400 & 600 & 360 & 19.4 & 5 & 0.36 \\
\hline
\end{tabular}
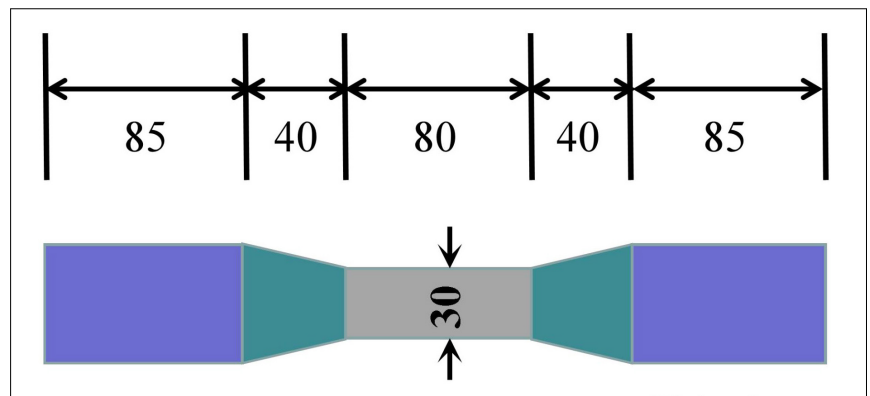

Unit: $\mathrm{mm}$

Plain view

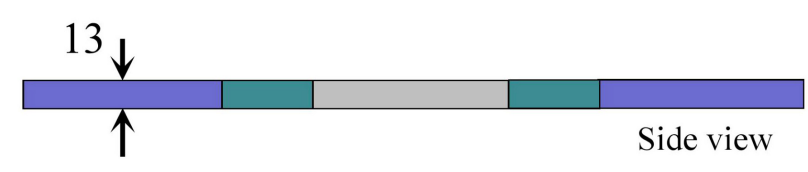

FIGURE 3 | Dimensions of dumbbell specimens.

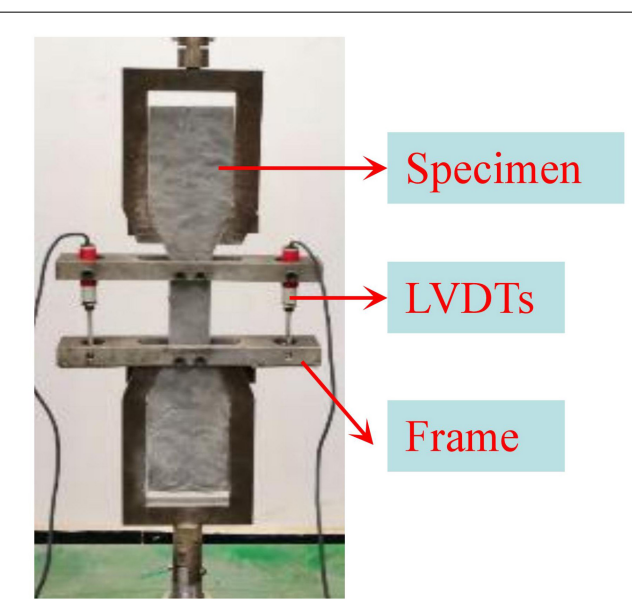

FIGURE 4 | Test setup of uniaxial tensile test.

experimental program of compressive and tensile tests is listed in Table 2.

\section{Experimental Setup and Procedure}

Figure 4 shows the setup of uniaxial tensile test. The alignment of whole setup was specially adjusted before loading to avoid the eccentric loading. The tensile loading speed was kept at $0.5 \mathrm{~mm} / \mathrm{min}$ according to Japan Society of Civil Engineers [JSCE] (2008) with a $50 \mathrm{~N}$
TABLE 2 | Test program of HDCC with different replacement ratios of RP.

\begin{tabular}{lccc}
\hline Mixture proportions & \multicolumn{2}{c}{ Compressive test } \\
\cline { 2 - 3 } & test & Tensile \\
\hline HDCC-RP-Reference to HDCC-RP-60\% & 5 & 4 \\
\end{tabular}
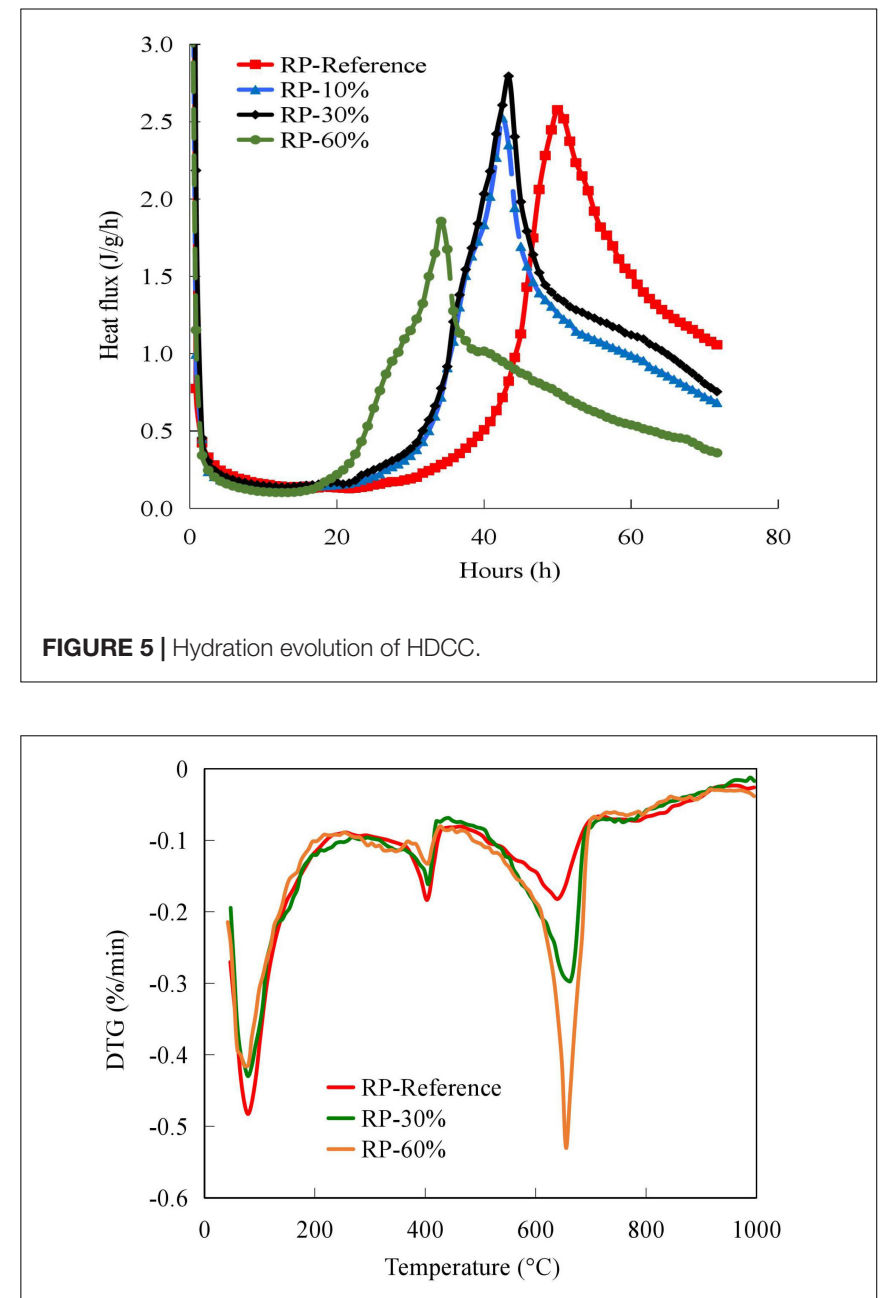

FIGURE 6 | DTG analysis of HDCC.

preloading. The loading capacity of test machine is $50 \mathrm{kN}$. A light-weight frame holding two symmetrically installed transducers (LVDTs) was attached to the dumbbell-shaped 
specimen to determine the displacement of specimen under tension. The tensile strain capacity of HDCC was calculated by the average reading of two LVDTs.

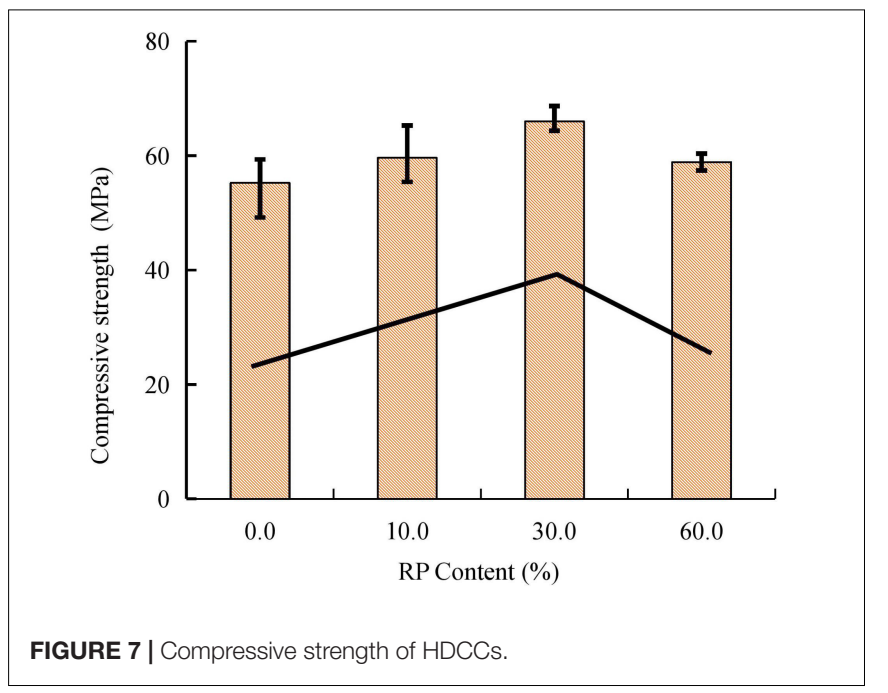

\section{RESULTS AND DISCUSSION}

\section{Isothermal Calorimetry}

The isothermal calorimetry was utilized to measure the hydration evolution of HDCC matrices under different RP contents, i.e., the replacement ratio from 10 to $60 \%$ of cement. Figure 5 shows the normalized heat flux under unit weight of binder material. The addition of RP accelerates the hydration rate and it is demonstrated that the dormant period of HDCC-RP- $60 \%$ matrix was shortest due to the existence of $\mathrm{CaCO}_{3}$ as the main compound of RP, which is considered to act as the accelerating seeds to the formation of tricalcium silicate $\left(\mathrm{C}_{3} \mathrm{~S}\right)$ (Nehdi et al., 1996). The hydration activity of the four HDCC matrices mainly happened in the first $72 \mathrm{~h}$, after which it decreased generally with curing age. The heat flux peak of HDCC matrices generally declined with the RP content (Figure 5), while the peaks of RP$10 \%$ and RP-30\% were comparable to or even higher than that of the reference matrix.

\section{Phase Development Analysis}

The DTG results of HDCC matrices with different RP replacement ratios at $28 \mathrm{~d}$ were shown in Figure 6. Three

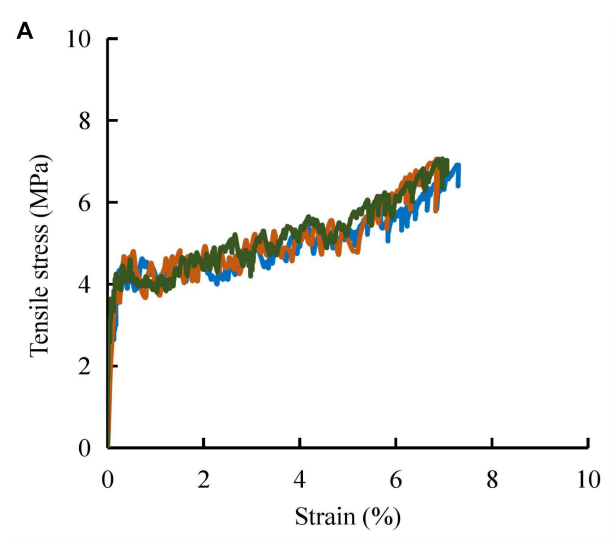

HDCC-Reference

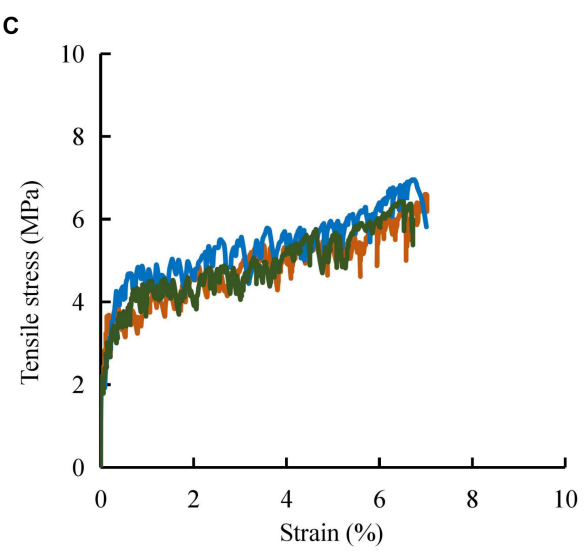

HDCC-RP- $60 \%$

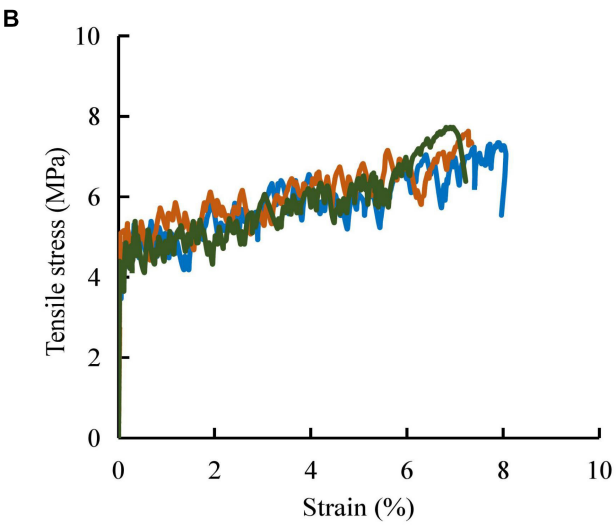

HDCC-RP-30\%

D

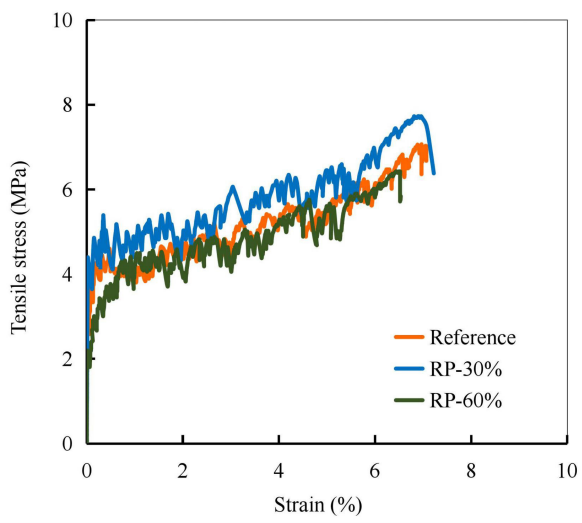

Typical tensile stress-strain curves

FIGURE 8| Tensile stress-strain curves of HDCCs. (A) HDCC-Reference. (B) HDCC-RP-30\%. (C) HDCC-RP-60\%. (D) Typical tensile stress-strain curves. 
A

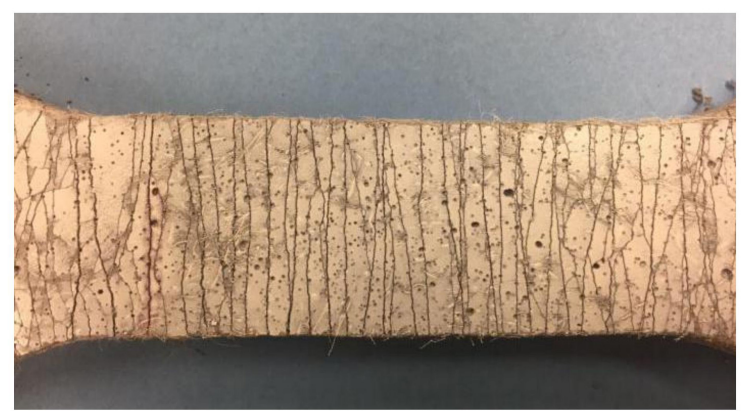

HDCC-Reference
B

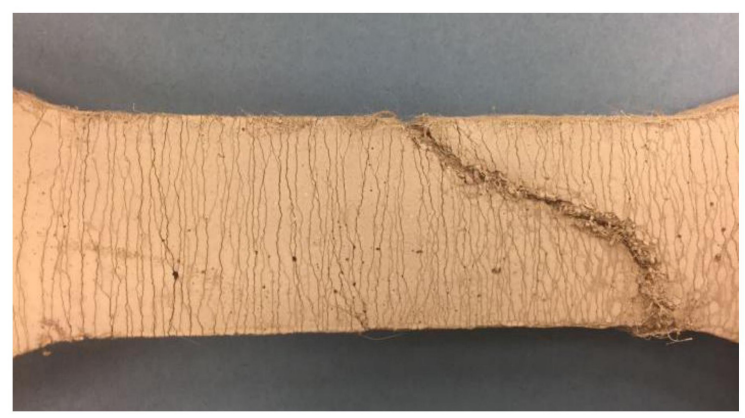

HDCC-RP-30\%

FIGURE 9 | Crack pattern of HDCCs. (A) HDCC-Reference. (B) HDCC-RP-30\%.

significant peaks could be observed: the first peak is around $200^{\circ} \mathrm{C}$, mainly related to the dehydration of ettringite; the second peak around $450^{\circ} \mathrm{C}$ is the dehydroxylation of $\mathrm{Ca}(\mathrm{OH})_{2}$; and the third peak around $500-800^{\circ} \mathrm{C}$ is the decarbonization of $\mathrm{CaCO}_{3}$ (Huang et al., 2017).

The peaks of $\mathrm{CaCO}_{3}$ in different matrices increased significantly with the larger amount of RP, while the peak of $\mathrm{Ca}(\mathrm{OH})_{2}$ of HDCC-RP- $60 \%$ was lower than those of HDCCReference and HDCC-RP-30\% at $28 \mathrm{~d}$ due to the significant reduction in cement and the potential pozzolanic reaction of RP in HDCC-RP-60\%.

\section{Compressive Properties of HDCCs}

Figure 7 displays the compression strength of HDCCs at $28 \mathrm{~d}$. The average strength value of reference specimen was $55.23 \mathrm{MPa}$ and it raised to $66.0 \mathrm{MPa}$ at the replacement ratio of $30 \%$. The strength evolution of RP-amended HDCCs indicated that an appropriate amount of RP would promote the compression strength owing to its pozzolanic and filler effect. However, excessive RP, which meant an excessive replacement of cement up to $60 \%$ would damage the compressive strength to some extent and compressive strength of HDCC-RP- $60 \%$ is $58.45 \mathrm{MPa}$.

\section{Tensile Stress-Strain Curves and Tensile Properties}

Figure 8 displays the tensile stress-strain relationships of HDCCs with different RP replacement ratios. The HDCC specimens in four cases show a robust strain-hardening performance. The tensile peak stress of HDCC-Reference was 7.00 $\mathrm{MPa}$, which was close to the value of HDCC-RP-10\% but lower than that of HDCC-RP-30\% (i.e., 7.57 MPa). Moreover, the addition of RP did not sacrifice the tensile strain capacity of RP-HDCCs even up to the RP content of $60 \%$.

Figure 9 shows the crack distribution of HDCC specimens at the unloading stage. The average crack numbers are 37, 42, 43, and 48 for HDCC-RP-Reference, HDCC-RP-10\%, HDCCRP-30\%, and HDCC-RP-60\%, respectively. The cracks evenly spread along the gauge length with an average crack spacing of $2.16 \mathrm{~mm}$ for HDCC-RP-Reference, $1.86 \mathrm{~mm}$ for HDCC-RP-30\%

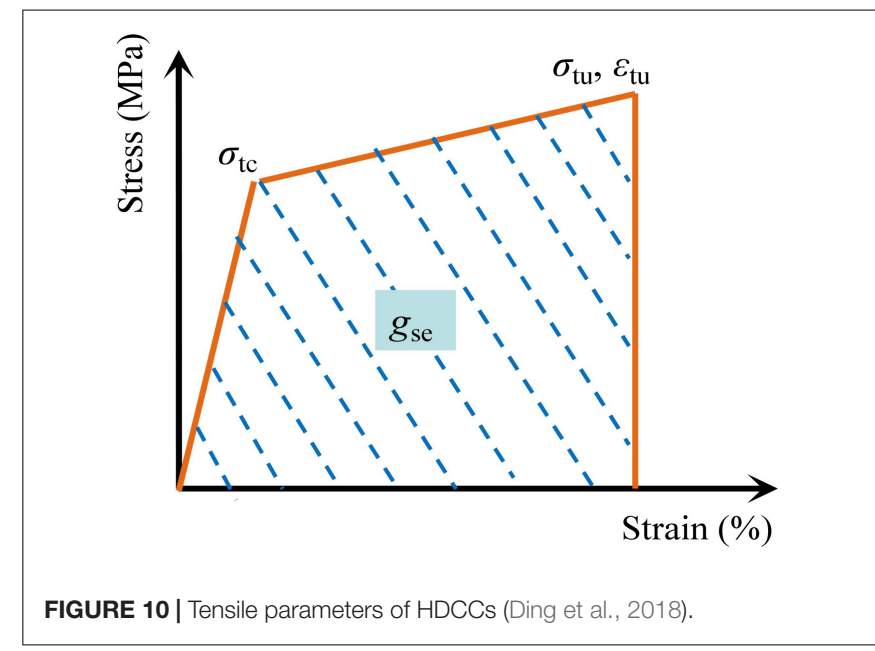

and $1.67 \mathrm{~mm}$ for HDCC-RP-60\%, respectively. The mixing of RP boosted the crack development leading to a larger crack number and consequently a smaller the crack spacing, which may be due to the increase in interfacial stress between fiber and matrix.

The tensile parameters including the initial cracking stress $\sigma_{t c}$, peak stress $\sigma_{\text {tu }}$, strain capacity and strain energy $g_{\text {se }}$ are shown in Figure 10. Detailed definitions of these parameters could be referred to Ding et al. (2018).

Figure 11 summarizes the tensile parameters of HDCCs under different replacement ratios. The peak stress $\sigma_{\text {tu }}$ increased generally from 7.0 MPa of HDCC-RP-Reference to 7.09 $\mathrm{MPa}$ of HDCC-RP-10\%, and then to 7.57 MPa of HDCC-RP-Reference$30 \%$. It is noticed that the $\sigma_{\text {tu }}$ of HDCC-RP- $60 \%$ (6.66 MPa) was only $5.5 \%$ lower than that of the HDCC-RP-Reference. The high replacement ratio of cement by $\mathrm{RP}$ did not compromise the strength development of HDCC, but significantly increased its greenness and reduced its impact on the environment. The initial stress $\sigma_{\text {tc }}$ shared a similar tendency with the $\sigma_{\text {tu }}$ of HDCCs (see in Figure 11A).

The addition of RP had positive influence on the tensile strain capacity up to the replacement ratio of $30 \%$ due to the 

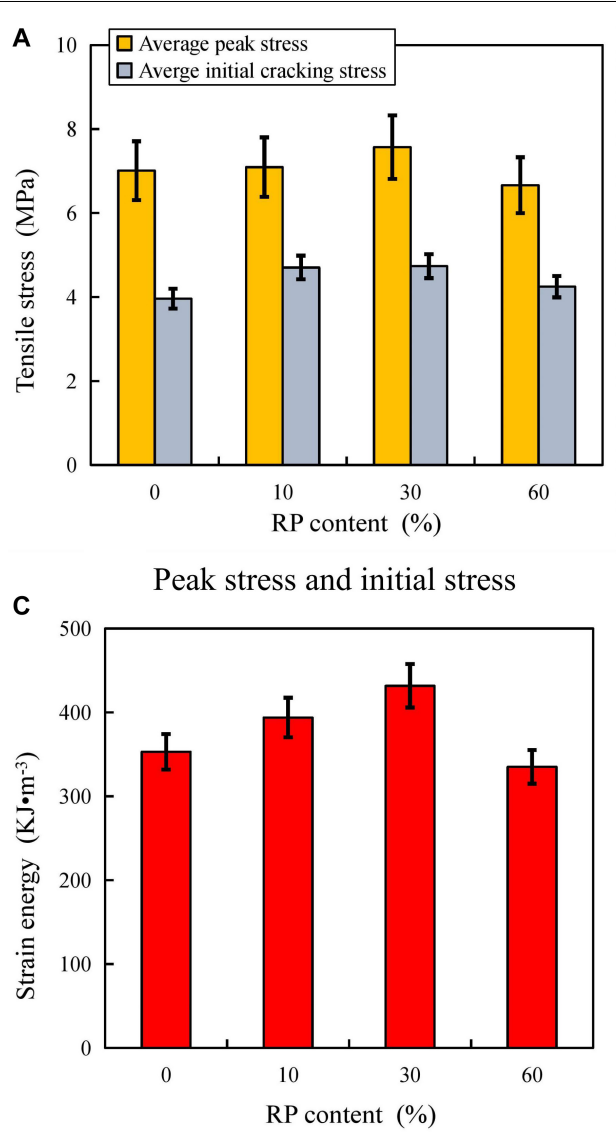

Strain energy

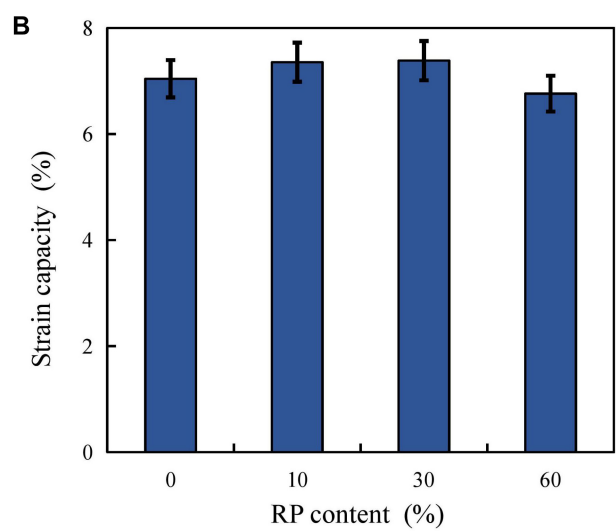

Strain capacity

D

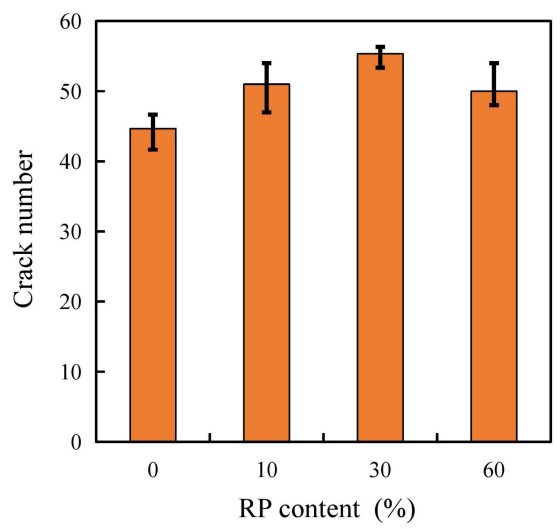

Crack number

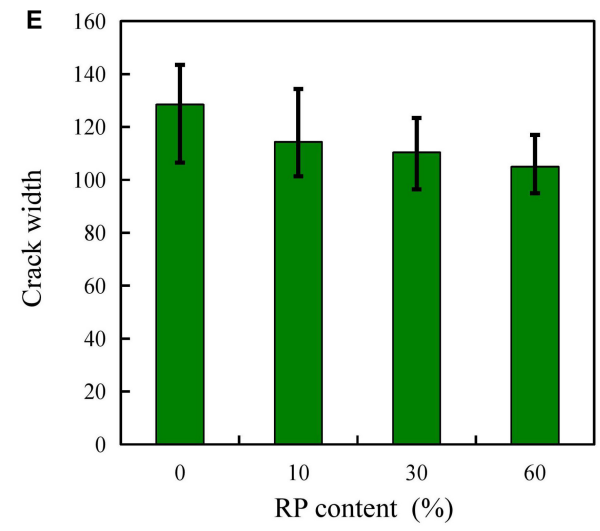

Crack width

FIGURE 11 | Tensile parameters of HDCCs with different RP replacement ratios. (A) Peak stress and initial stress. (B) Strain capacity. (C) Strain energy. (D) Crack number. (E) Crack width.

enhancement of interfacial stress (see in Figure 11B). However, a further increase of the RP content up to $60 \%$ slightly weakened the strain capacity of HDCC-RP- $60 \%$, which could be attributed to the smaller crack width in HDCC-RP-60\% (see in Figure 11E). The strain energy $g_{\text {se }}$, kept almost constant to HDCC-RP-30\% at around $430 \mathrm{~kJ} / \mathrm{m}^{3}$ and then decreased apparently to $335 \mathrm{~kJ} / \mathrm{m}^{3}$ of HDCC-RP- $60 \%$ due to the combination of lower $\sigma_{\mathrm{tu}}$ and $\varepsilon_{\mathrm{tu}}$. The $g_{\text {se }}$ of HDCC was significantly greater than those of conventional fiber-reinforced concrete and ultra-high performance concrete at the range of $50-100 \mathrm{~kJ} / \mathrm{m}^{3}$ (Wille et al., 2011).

In addition, it is interpreted from Figures 11D,E that the reduction in $\varepsilon_{\mathrm{tu}}$ of HDCC-RP- $60 \%$ was the result of finer crack width of RP-amended HDCCs. The RP particle size was smaller than that of cement particle, which would help to establish a 
A

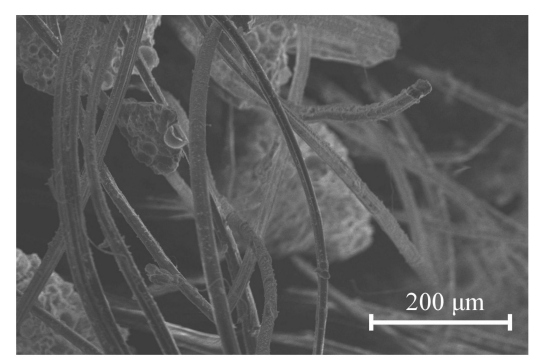

Fiber surface (HDCC-RP-Reference)

C

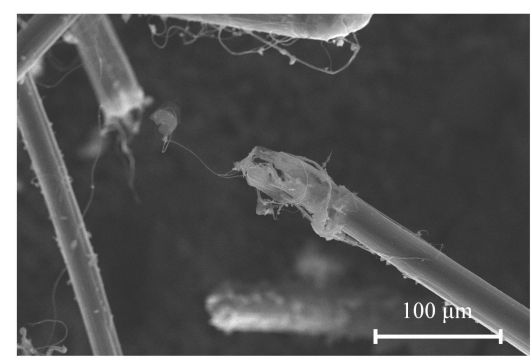

Fiber fibrillation (HDCC-RP-30\%)
B

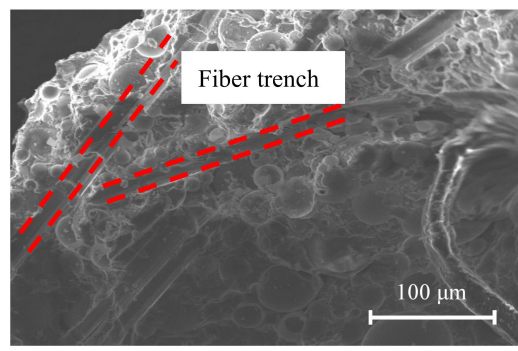

Fiber/matrix interface (HDCC-RP-Reference)

D

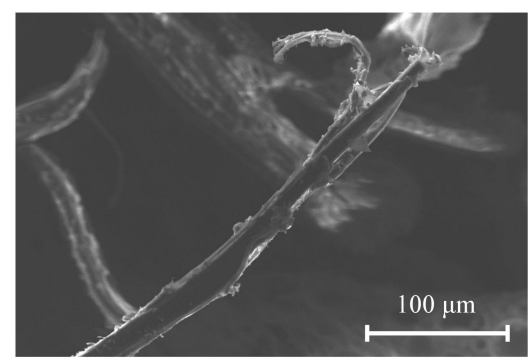

Fiber surface (HDCC-RP-30\%)

FIGURE 12 | Morphology of HDCCs. (A) Fiber surface (HDCC-RP-Reference). (B) Fiber/matrix interface (HDCC-RP-Reference). (C) Fiber fibrillation (HDCC-RP-30\%). (D) Fiber surface (HDCC-RP-30\%).

denser matrix, leading to tinier crack width. It is calculated that the average crack width of HDCC-RP- $60 \%$ was around $120 \mu \mathrm{m}$, which was close to that of PVA-ECC (Li, 2003).

\section{Morphology of Fiber in HDCC}

Figure 12 shows the morphology of fibers and fiber/matrix interface of HDCC-RP-Reference and HDCC-RP-30\% by scanning electron microscope (SEM) observation. The SEM samples were taken from the ruptured surface of the dumbbell specimens. The majority of PE fibers were stretched out of the HDCC matrix with a blunt end (see in Figure 12A) or slightly damaged (see in Figure 12C). However, the fibers of HDCC-RP-30\% were damaged more severely and led to a higher tensile strength (see in Figure 12D).

\section{CONCLUSION}

The impact of RP on hydration, phase development, compressive strength and tensile properties of HDCC were studied in the present research. Three replacement ratios of RP ranging from 10, 30 to $60 \%$ were employed. The detailed conclusions are listed as follows.

(1) The addition of RP accelerates the hydration rate and it is demonstrated that the dormant period of HDCC-RP- $60 \%$ matrix was shortest due to the existence of $\mathrm{CaCO}_{3}$ as the main compound of RP, which is considered to act as the accelerating seeds. The peaks of $\mathrm{CaCO}_{3}$ in different matrices increased significantly with the larger amount of RP. However, the peaks of $\mathrm{Ca}(\mathrm{OH})_{2}$ decreased with higher $\mathrm{RP}$ contents due to the significant reduction in cement.

(2) All the HDCC mixtures demonstrated a robust strainhardening performance with evenly distributed cracks. The peak tensile stress and compressive strength of HDCCs increased with RP replacement ratio up to $30 \%$ due to a combination of pozzolanic and filler effect and these strengths decreased afterward. The crack number increased with RP contents, while the strain capacity of HDCC-RP-60\% decreased slightly due to its the tinier crack width. The morphology of PE fiber of the tested specimen was investigated by the SEM analysis. The optimal replacement ratio of RP for future practical application is suggested for $30 \%$ provided with the similar particle size of current research, when the mechanical performance is considered.

\section{DATA AVAILABILITY STATEMENT}

The raw data supporting the conclusions of this article will be made available by the authors, without undue reservation.

\section{AUTHOR CONTRIBUTIONS}

JJ, HS, and LJ were responsible for designing the experiment scheme, test execution, data analysis, and writing the original manuscript. HR was responsible for guiding the experiment scheme and revision of the manuscript. YZ and YL participated 
in the experimental scheme design. All authors contributed to the article and approved the submitted version.

\section{FUNDING}

The authors are grateful for the financial support received from the National Natural Science Foundation of China

\section{REFERENCES}

ASTM International (2008). ASTM Technical Committee Members and Staff Attend Concrete Industry Event in Colombia. ASTM Standardization News: West Conshohocken, PA, 36.

Ding, Y., Yu, J. T., Yu, K. Q., and Xu, S. L. (2018). Basic mechanical properties of ultra-high ductility cementitious composites: from $40 \mathrm{MPa}$ to $120 \mathrm{MPa}$. Compos. Struct. 185, 634-645. doi: 10.1016/j.compstruct.2017. 11.034

Huang, W., Kazemi-Kamyab, H., Sun, W., and Scrivener, K. L. (2017). Effect of cement substitution by limestone on the hydration and microstructural development of ultra-high performance concrete (UHPC). Cem. Concr. Comp. 77, 86-101. doi: 10.1016/j.cemconcomp.2016.12.009

Japan Society of Civil Engineers [JSCE] (2008). Recommendations for Design and Construction of High Performance Fiber Reinforced Cement Composites with Multiple Fine Cracks. Tokyo: Japan Society of Civil Engineers, 1-16.

Ji, J., Yu, D. Y., Jiang, L. Q., Xu, Z. C., Liu, Y. C., and Zhang, S. L. (2019). Effect of post-fire curing on the compressive properties of fire-damaged ultra-high toughness cementitious composites. J. Test. Eval. 47, 140-152.

Li, H., Xiao, H. G., and Ou, J. P. (2007). Effect of compressive strain on electrical resistivity of carbon black-filled cement-based composites. Cem. Concr. Comp. 28, 824-828. doi: 10.1016/j.cemconcomp.2006.05.004

Li, H., Xu, S., and Leung, C. K. (2009). Tensile and flexural properties of ultrahigh toughness cemontious composite. J. Wuhan Univ. Technol. 24, 677-683. doi: 10.1007/s11595-009-4677-5

Li, V. C. (2003). On engineered cementitious composites (ECC). J. Adv. Concr. Technol. 1, 215-230.

Liu, J. C., Tan, K. H., and Zhang, D. (2017). Multi-response optimization of postfire performance of strain hardening cementitious composite. Cem. Concr. Comp. 80, 80-90. doi: 10.1016/j.cemconcomp.2017.03.001

Liu, Q., Tong, T., Liu, S., Yang, D., and Yu, Q. (2014). Investigation of using hybrid recycled powder from demolished concrete solids and clay bricks as a pozzolanic supplement for cement. Constr. Build. Mater. 73, 754-763. doi: 10.1016/j.conbuildmat.2014.09.066

Nehdi, M., Mindess, S., and Aitcin, P. C. (1996). Optimization of high strength limestone filler cement mortars. Cem. Concr. Res. 26, 883-893. doi: 10.1016/ 0008-8846(96)00071-3 (grant no. 51178087); The Natural Science Foundation of Heilongjiang Province (grant no. LH2020E018); Opening Fund for Key Laboratory of The Ministry of Education for Structural Disaster and Control of Harbin Institute of Technology (grant no. HITCE201908); Scientific Research Fund of Institute of Engineering Mechanics, China Earthquake Administration (grant no. 2020D07), and Northeast Petroleum University Guided Innovation Fund (grant no. 2020YDL-02).

Sun, Z., Liu, F., Tong, T., Qi, C., and Yu, Q. (2017). Hydration of Concrete Containing Hybrid Recycled Demolition Powders. J. Mater. Civil Eng. 29:04017037. doi: 10.1061/(asce)mt.1943-5533.0001842

Wang, Y., Wei, L., Yu, J., and Yu, K. (2019). Mechanical properties of high ductile magnesium oxychloride cement-based composites after water soaking. Cem. Concr. Comp. 97, 248-258. doi: 10.1016/j.cemconcomp.2018.12.028

Wille, K., Naaman, A., and Montesinos, G. (2011). Ultra-high performance concrete with compressive strength exceeding $150 \mathrm{MPa}$ (22 ksi): a simpler way. J. ACI Mater. 108, 46-54.

Xiao, J., Ma, Z., and Ding, T. (2016). Reclamation chain of waste concrete: a case study of Shanghai. Waste Manage. 48, 334-343. doi: 10.1016/j.wasman.2015. 09.018

Yang, E. H., Yang, Y., and Li, V. C. (2007). Use of high volumes of fly ash to improve ECC mechanical properties and material greenness. J. ACI Mater. 104, 620-628.

Yu, J., Li, H. D., Leung, C. K., Lin, X., Lam, J. Y., Sham, I. M., et al. (2017). Matrix design for waterproof engineered cementitious composites (ECCs). Constr. Build. Mater. 139, 438-446. doi: 10.1016/j.conbuildmat.2017.02.076

Yu, K. Q., Lu, Z. D., Dai, J. G., and Shah, S. P. (2020). Direct tensile properties and stress-strain model of UHP-ECC. J. Mater. Civil Eng. 32:04019334. doi: 10.1061/(asce)mt.1943-5533.0002975

Yu, K., Li, L., Yu, J., Wang, Y., Ye, J., and Xu, Q. (2018). Direct tensile properties of engineered cementitious composites: a review. Constr. Build. Mater. 165, 346-362. doi: 10.1016/j.conbuildmat.2017.12.124

Zhang, Z., and Zhang, Q. (2018). Matrix tailoring of engineered cementitious composites (ECC) with non-oil-coated, low tensile strength PVA fiber. Constr. Build. Mater. 161, 420-431. doi: 10.1016/j.conbuildmat.2017.11.072

Conflict of Interest: The authors declare that the research was conducted in the absence of any commercial or financial relationships that could be construed as a potential conflict of interest.

Copyright (C) $2021 \mathrm{Ji}$, Song, Jiang, Ren, Zhang and Liu. This is an open-access article distributed under the terms of the Creative Commons Attribution License (CC BY). The use, distribution or reproduction in other forums is permitted, provided the original author(s) and the copyright owner(s) are credited and that the original publication in this journal is cited, in accordance with accepted academic practice. No use, distribution or reproduction is permitted which does not comply with these terms. 